\title{
Arsenic speciation in the dispersible colloidal fraction of soils from a mine-impacted
}

creek

Susana Serrano $^{\mathrm{a}}$, Miguel Angel Gómez-González ${ }^{\mathrm{b}}$, Peggy A. O’ Day ${ }^{\mathrm{c}}$, Francisco Laborda ${ }^{\mathrm{d}}$, Eduardo Bolea $^{\mathrm{d}}$, and Fernando Garrido ${ }^{\mathrm{b}}$

${ }^{a}$ Institute of Agrochemistry and Food Technology, CSIC, Agustín Escardino 7, 46980

Paterna Valencia, Spain

${ }^{\mathrm{b}}$ National Museum of Natural Sciences, CSIC, José Gutiérrez Abascal 2, 28006 Madrid, Spain

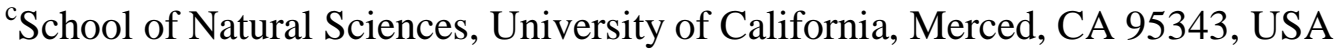

${ }^{\mathrm{d}}$ Group of Analytical Spectroscopy and Sensors (GEAS), Institute of Environmental Sciences (IUCA), University of Zaragoza, Pedro Cerbuna 12, 50009 Zaragoza, Spain

* Corresponding author (fernando.garrido@mncn.csic.es); Tel.: +34 917452500; Fax: +34

\section{ABSTRACT}

Arsenic and iron speciation in the dispersible colloid fraction (DCF; 10-1000 nm) from an As-rich mine waste pile, sediments of a streambed that collects runoff from waste pile, the 
combining asymmetrical-flow field-flow fractionation (AsFlFFF)/inductively-coupled plasma-mass spectrometry (ICP-MS), transmission electron microscopy (TEM) and X-ray absorption (XAS) spectroscopy. Calcium, Fe and As (Fe/As molar ratio 1) were the main components of the DCF from waste pile. TEM/EDS and As and Fe XAS analysis revealed the presence of nanoparticle scorodite in this same DCF, as well as Fe nanoparticles in all samples downstream of the waste pile. Arsenic and Fe XAS showed As(V) adsorbed onto nanoparticulate ferrihydrite in the DCF of downstream samples. Micro-X-ray fluorescence indicated a strong correlation between $\mathrm{Fe}$ and $\mathrm{As}$ in phyllosilicate $/ \mathrm{Fe}^{3+}$ (oxi)hydroxide aggregates from the sediment pond. Fractionation analysis showed the mean particle size of the DCF from the streambed sample to be smaller than that of the streambed subsoil and sediment ponds samples. These results show that an important and variable fraction of As may be bound to dispersible colloids that can be released from contaminated soils and transported downstream in natural systems.

\section{Introduction}

Understanding the release of colloids from soils and sediments, and their association with contaminants, is essential when evaluating pollutant transport processes [1-7]. The in situ mobilization and transport of colloids in soils depends on the latters' physico-chemical characteristics (presence of organic matter, clay minerals, $\mathrm{pH}$, ionic strength, etc.), and the reigning hydrodynamic conditions (flow velocity and soil saturation) $[8,9]$. Once a colloid has been mobilized, its transport is controlled by its size and stability in solution, i.e., its tendency to aggregate. Aggregation is controlled mainly by the balance of attractive and repulsive forces between particles [10]. The presence in solution of ions of opposite charge to those on the surface of a colloid, and an increment in the ionic strength of the soil solution and/or any runoff, increases aggregation, while the surface coating of colloids with organic matter enhances colloid stability [11]. Colloids can 
strongly bind metals and other pollutants in soils and aquifers. In soils and sediments impacted by mining wastes, the mobility of As and other metals is affected by the release and transport of nanoparticles from the soils and As-colloid adsorption phenomena.

The characterization of natural colloids requires the use of fractionation and analytical techniques that minimize sample perturbation. One option is asymmetrical-flow field-flow fractionation (AsFlFFF), in which colloids are separated according to their diffusion against a flow-field perpendicular to a carrier flow $[12,13]$. The AsFlFFF has been used couple to inductively-coupled plasma-mass spectrometry (ICP-MS) to determine the elemental composition of colloids and their particle size distribution $[12,14$, 15]. This allows the relationship between trace metal(oids) concentrations and colloid particle size to be established. However, elemental analysis alone provides no information about the molecular-scale chemical association of metal(oids) and colloids, which determines the potential bioavailability and health impacts of dispersed contaminants, and helps predict metal-colloid stability.

Synchrotron X-ray methods have been used to characterize natural colloids and their association with As in mine systems. Slowey et al. [16] described the transport of As(V) when adsorbed onto colloidal ferrihydrite and jarosite in columns packed with mine tailings. Zanker et al. [17] showed that mine wastes contained As within nanometer jarosite-like particles. Additionally, AsFIFFF/ICP-MS has revealed colloid-bound As in abandoned mine tailings [7], while selective sequential extraction, high resolution ICP-MS and transmission electron microscopy (TEM) [18] have revealed nanoparticles sequestered by metal-contaminated mine sediments.

In this work, the dispersible colloid fractions (DCFs) $(10-1000 \mathrm{~nm})$ of a mine waste pile and its adjacent sediments and soils were examined to determine their elemental and mineral composition as a function of colloid size. The As and Fe speciation was also 
examined, as was the partitioning of As and companion metals between the DCF and the fraction of their total amount that remained dissolved. Understanding the relationship between the composition of natural colloids, and soils and sediments properties, as well as the colloid-contaminant association, is crucial in contaminant transport studies.

\section{Materials and methods}

\subsection{Sample collection and description}

Samples were collected from an abandoned smelting factory in Guadalix de la Sierra (Madrid, Spain) where arsenopyrite encapsulated in quartz was mined and processed for wolfram extraction during the Second World War (Fig. 1). Arsenic-rich residues were dumped nearby and pose a public health problem [19]. Four types of sample were collected: (1) samples (0-10 cm depth) from the main waste pile (WP) [19] (dumped on the soil surface); (2) sediments from the bed of a small stream originating at the WP that collects runoff (samples RB2 at $17 \mathrm{~m}$ from the WP and at $0-5 \mathrm{~cm}$ depth, and RB at $26 \mathrm{~m}$ from WP and at 0-10 cm depth ); (3) the streambed subsoil (SS) (at $26 \mathrm{~m}$ from the WP and at $10-20 \mathrm{~cm}$ depth of), and (4), the sediment from a downstream pond (SP) (at $58 \mathrm{~m}$ from the WP and at a depth of $0-5 \mathrm{~cm}$ ) that collects runoff from the stream (Fig. 1).

Characterization methods are described in the Electronic Annex (EA).

\subsection{Dispersible colloid fraction: preparation and pre-fractionation}

The maximum amount $\left(\mathrm{mg} \mathrm{kg}^{-1}\right.$ soil) of potentially releasable colloids from the different samples was termed dispersible colloid fraction (DCF). The DCF was extracted from all samples based on a protocol described elsewhere [13] with modifications (Fig. 2). Preparation and pre-fractionation methods are given in EA.

\subsection{Colloid characterization}

\subsubsection{AsFIFFF-ICP-MS}


The distribution of particle size and the concentration of associated metal(oid)s in the $<1000 \mathrm{~nm}$ fraction was determined by AsFlFFF-ICP-MS (see Table EA-2 for operating conditions).

In AsFlFFF, a surfactant (SDS, 0.01\% w/v) adjusted to $\mathrm{pH} 4.5$ (close to the original $\mathrm{pH}$ ) was used as a carrier solution for the $<1000 \mathrm{~nm}$ fraction from the WP, RB2, RB and SS samples; for the SP sample it was adjusted to $\mathrm{pH}$ 6.5. The carrier was degassed by an on-line vacuum degasser prior to use. Sample loops of 20 and $100 \mu \mathrm{L}$ were used throughout depending on the element concentrations detected [20]. Colloid sizes and calibration standards; (details in EA) were detected using a UV-vis diode array detector (Shimadzu). On-line multi-element quantification was performed using an ELAN DRC-e ICP-MS (Perkin Elmer). The samples were introduced into the ICP-MS using a glass concentric slurry nebulizer and a cyclonic spray chamber (Glass Expansion). An internal standard solution of $50 \mathrm{ng} \mathrm{mL}{ }^{-1} \mathrm{Rh}$ (Merck) was pumped into the mobile phase at $0.3 \mathrm{ml}$ $\min ^{-1}$ for correction of instrumental drift. ICP-MS data acquisition and recovery calculation details are in Table EA-3.

\subsubsection{Element concentrations}

The element concentrations of the DCF of each sample were analyzed using an OPTIMA 4300DV ICP-optical emission spectrometer (ICP-OES) (Perkin-Elmer) after microwave digestion with $\mathrm{HF}+\mathrm{HNO}_{3}+\mathrm{HCl}$ followed by $\mathrm{H}_{3} \mathrm{BO}_{3}$. The DFs $(<10 \mathrm{~nm}$ fractions) were analyzed using an ELAN DRC-e ICP-MS spectrometer (Perkin Elmer).

The total carbon concentration in the DCF was determined by combustion using a 2400 Series II CHNS/O Elemental Analyzer (Perkin Elmer). The mass retained on the ultrafiltration membranes was determined gravimetrically.

\subsubsection{Transmission electron microscopy}


Aliquots of the $<1000 \mathrm{~nm}$ fraction from the WP, RB and SS were examined using a CM200FEG transmission electron microscope (TEM) (Philips,) (See EA).

\subsubsection{Microfocused synchrotron X-ray fluorescence}

Chemical mapping was performed on the $<1000 \mathrm{~nm}$ SP fraction using synchrotron microfocused X-ray fluorescence $(\mu \mathrm{XRF})$ at the Stanford Synchrotron Radiation Lightsource (SSRL) laboratory (on Beamline 2-3) (See EA).

\subsubsection{Arsenic and iron X-ray absorption spectroscopy}

Arsenic and Fe K-edge spectra of DCF samples, and of a reference DCF sample of As adsorbed onto ferrihydrite (termed As(V)_Fh_coll; see EA for details), were collected at the European Synchrotron Radiation Facility (ESRF; 6 GeV, 100 mA) (bending-magnet BM25A Beamline). Methods are described in EA. Spectra were analyzed using Athena software [21] for linear combination fits, and EXAFSPAK software [22] for shell-by-shell fits. Data collection and analysis are in EA.

\section{Results}

\subsection{DCF composition and size distribution}

Table 1 shows element concentrations of the DCF of the different samples. Figure 3 shows their relative molar proportions. Calcium was the major element $\left(3.5 \mathrm{~mol} \mathrm{~kg} \mathrm{coll}{ }^{-1}\right)$ of the DCF of the WP sample $\left(\mathrm{WP}_{\mathrm{DCF}}\right)$, followed by As and Fe with a Fe/As mole ratio 1. Iron and $\mathrm{Al}$ were the major elements in $\mathrm{RB} 2_{\mathrm{DCF}}, \mathrm{RB}_{\mathrm{DCF}}$ and $\mathrm{SS}_{\mathrm{DCF}}$. Carbon accounted for $39 \%$ of the element composition in $\mathrm{SP}_{\mathrm{DCF}}$, and $\mathrm{Al} 48 \%$ (Fig. 3). The $\mathrm{RB}_{\mathrm{DCF}}$ had the highest $\mathrm{Fe}$ concentration of all samples while the $\mathrm{SS}_{\mathrm{DCF}}$ had the highest $\mathrm{Al}$ concentration. The $\mathrm{RB}_{\mathrm{DCF}}$ and $\mathrm{SP}_{\mathrm{DCF}}$ had slightly lower (and similar) Al concentrations. The $\mathrm{RB}_{\mathrm{DCF}}$ had the highest $\mathrm{Fe} / \mathrm{Al}$ molar ratio, followed by $\mathrm{RB} 2_{\mathrm{DCF}}, \mathrm{SP}_{\mathrm{DCF}}$ and $\mathrm{SS}_{\mathrm{DCF}}$.

The As concentration fell with distance from the WP; indeed, a large difference in As concentration was seen between the $\mathrm{WP}_{\mathrm{DCF}}\left(0.25 \mathrm{~mol} \mathrm{~kg} \mathrm{coll}^{-1}\right)$ and the $\mathrm{RB} 2_{\mathrm{DCF}}(0.08 \mathrm{~mol}$ 
$\mathrm{kg} \mathrm{coll}{ }^{-1}$ ), falling further for the $\mathrm{RB} 2_{\mathrm{DCF}}, \mathrm{RB}_{\mathrm{DCF}}, \mathrm{SS}_{\mathrm{DCF}}$ and $\mathrm{SP}_{\mathrm{DCF}}$ (Fig. 1). An increase in the Fe/As molar ratio was observed from the WP to the SP positions (Table 2).

Calcium represented $12 \%$ of the elemental composition of the $\mathrm{RB} 2{ }_{\mathrm{DCF}}$ but less than $2 \%$ of that of the $\mathrm{RB}_{\mathrm{DCF}}, \mathrm{SS}_{\mathrm{DCF}}$ and $\mathrm{SP}_{\mathrm{DCF}}$ (Fig. 3). Lead was only detected in $\mathrm{WP}_{\mathrm{DCF}} ; \mathrm{Cu}$ and $\mathrm{Zn}$ were below the detection limit. The $\mathrm{SS}_{\mathrm{DCF}}$ showed the highest $\mathrm{Cu}$ concentration of the downstream samples $\left(0.05 \mathrm{~mol} \mathrm{~kg}^{-1}\right)\left(\mathrm{SS}_{\mathrm{DCF}}>\mathrm{RB}_{\mathrm{DCF}}>\mathrm{SP}_{\mathrm{DCF}}\right)$, while the $\mathrm{RB} 2_{\mathrm{DCF}}$ showed the highest $\mathrm{Zn}$ concentration $\left(0.01 \mathrm{~mol} \mathrm{~kg}^{-1}\right)\left(\mathrm{RB} 2_{\mathrm{DCF}}>\mathrm{RB}_{\mathrm{DCF}}>\mathrm{SS}_{\mathrm{DCF}}>\mathrm{SP}_{\mathrm{DCF}}\right)$.

Figure 4 shows the AsFlFFF-ICP-MS fractograms for the RB, SS and SP $<1000$ $\mathrm{nm}$ fractions. Given the low colloid mass (per mass of bulk sample) of the $\mathrm{WP}_{\mathrm{DCF}}$ and $\mathrm{RB} 2 \mathrm{DCF}$ (2634 $\mathrm{mg} \mathrm{kg}^{-1}$ and $840 \mathrm{mg} \mathrm{kg}^{-1}$ respectively), and the high conductivity of the WP suspension (Table EA-1) no reliable fractograms were obtained. The $<1000 \mathrm{~nm}$ fractions had different colloid size distributions but similar $\mathrm{Al}, \mathrm{Ca}, \mathrm{Fe}, \mathrm{As}, \mathrm{Cu}, \mathrm{Zn}$ and $\mathrm{Pb}$ concentration distributions. The $<1000 \mathrm{~nm}$ fraction of RB was characterized by particle size and element concentration maxima at $\sim 30 \mathrm{~nm}$; the maximum element concentration was also associated with this particle size (Fig. 4a). The single-peak element concentration suggests particle homogeneity. For the $<1000 \mathrm{~nm}$ fraction of the SS sample, two maxima were observed in the colloid size distribution, at 55 and $175 \mathrm{~nm}$ (Fig. 4b). The SP fractogram showed a wide distribution with a broad maximum between 55 and $100 \mathrm{~nm}$ (Fig. 4c).

\subsection{TEM-EDX and $\mu X R F$}

Particulate scorodite ( $~ 80 \mathrm{~nm}$ in diameter) was observed and identified by TEMEDX in the $\mathrm{WP}_{\mathrm{DCF}}$ (Fig. 5a). In the RB2 $2_{\mathrm{DCF}}$, TEM-EDX showed particle aggregates of $<50$ $\mathrm{nm}$ and high concentrations of $\mathrm{Si}, \mathrm{Al}$ and $\mathrm{Fe}$, suggestive of clay minerals and $\mathrm{Fe}$ hydroxides (Fig. 5b). In the $\mathrm{RB}_{\mathrm{DCF}}, 30 \mathrm{~nm}$ Fe nanoparticles formed chains or aggregates associated with $\mathrm{Si}, \mathrm{Ca}, \mathrm{Mn}$ and $\mathrm{Cu}$ (Fig. 5c, 5d). Iron nanoparticles (10 nm) forming larger 
aggregates ( $\sim 50 \mathrm{~nm}$ in diameter) were observed in the $\mathrm{SS}_{\mathrm{DCF}}$ (Fig. 5e). Arsenic associated with Fe particles in the $\mathrm{SS}_{\mathrm{DCF}}$ was observed by EDX analysis (data not shown). The $\mathrm{SP}_{\mathrm{DCF}}$ contained aggregates of small nanoparticles $(\sim 10 \mathrm{~nm})$; $\mathrm{Fe}, \mathrm{Si}, \mathrm{Al}, \mathrm{Ca}, \mathrm{Mg}$ and As were detected by EDX, indicating these aggregates to be heterogeneous. Synchrotron $\mu \mathrm{XRF}$ maps (mapping area $1 \times 1 \mu \mathrm{m}^{2}$ ) of the $\mathrm{SP}_{\mathrm{DCF}}$ indicated a correlation between $\mathrm{As}$ and $\mathrm{Fe}$ in aggregated nanoparticles (150-250 nm) (Fig. 5g and h).

\subsection{Arsenic and iron XAS of colloids}

Normalized As XANES of three As reference spectra -natural scorodite [23], As absorbed onto ferrihydrite (As(V)_Fh; As/Fe ratio 0.012) [24], and colloid-extracted As absorbed onto ferrihydrite $(<1 \mu \mathrm{m})\left(\mathrm{As}(\mathrm{V}) \_\right.$Fh_coll; As/Fe ratio 0.09 [this study])- were compared with those of the DCF samples (Fig. 6). The As(V)_Fh and As(V)_Fh_coll reference spectra were similar, although their post-edge spectral features were not identical. The As K-edge XANES spectra of all DCF samples indicated that As was present only as As(V) (absorption maxima 11874.5-11875.5 eV) (Fig. 6). The XANES spectra of all DCF samples, except $\mathrm{WP}_{\mathrm{DCF}}$, resembled that of either As(V)_Fh or As(V)_Fh_coll, with small differences associated with a post-edge absorption feature at around $11895 \mathrm{eV}$ (Fig. 6). The LCF of the $\mathrm{WP}_{\mathrm{DCF}}$ As XANES spectrum indicated a mixture of scorodite (61\%) and As(V)_Fh (39\%) (Table 2). The XANES spectra of DCFs of the downstream samples were fit best using only the As(V)_Fh reference spectrum

\section{(Table 2).}

Shell-by-shell quantitative analysis of the $\mathrm{WP}_{\mathrm{DCF}}$ As EXAFS spectrum indicated a bonding environment for As similar to that of scorodite, with similar coordination numbers and interatomic distances (Table 2, Fig. 6). Fits to $\mathrm{RB}_{\mathrm{DCF}}$ and $\mathrm{SP}_{\mathrm{DCF}}$ spectra gave an As-Fe distance of 3.31-3.32 $\AA$, similar to that fit for the As(V)_Fh_coll reference spectrum. For comparison, the fit of As(V)_Fh_coll reference spectrum yielded an As-O first-shell 
distance of $1.69 \AA$ ( $\mathrm{N}_{\mathrm{As}-\mathrm{O}}=4$, fixed $)$ and an As-Fe distance of $3.28 \AA$. This As-Fe distance was shorter than the two As-Fe distances (3.38 and $3.52 \AA$ ) obtained from the fit of the reference spectrum of As sorbed to ferrihydrite (As(V)_Fh) (Table 2).

Linear combination fits of Fe XANES spectra showed that the $\mathrm{WP}_{\mathrm{DCF}}$ was dominated by scorodite $(83 \%)$ and an Fe(III)-oxide phase (16\%) that best matched the As(V)_Fh_coll reference spectrum (Fig. 7, Table 3). The two best-fit components for the $\mathrm{RB}_{\mathrm{DCF}}$ and $\mathrm{SS}_{\mathrm{DCF}}$ were smectite (SAz-1) and As(V)_Fh_coll (Fig. 7, Table 3). The $\mathrm{SP}_{\mathrm{DCF}}$ spectrum was fit best with reference illite (IMT-1 Fe) (60\%) and As(V)_Fh_coll (40\%) spectra. The RB2 $2_{\text {DCF }}$ spectrum was fit with only the As(V)_Fh_coll spectrum. The reference compounds used in the XANES analysis were also used in LCF of the Fe EXAFS spectra. The EXAFS LCFs overestimated crystalline mineral fractions such as illite compared with amorphous phases such as ferrihydrite because of the stronger second-neighbor backscattering in crystalline materials [25].

3.4. Composition of dispersible colloid and dissolved fractions and bulk sample properties

The bulk WP sample had low pH (3.25), and its main minerals were scorodite, gypsum, quartz and hematite (Table EA-1; Fig. EA-1). Chemical analysis revealed the $\mathrm{WP}_{\mathrm{DCF}}$ to have high As $\left(1.8 \mathrm{~mol} \mathrm{~kg}^{-1}\right), \mathrm{Fe}\left(3.5 \mathrm{~mol} \mathrm{~kg}^{-1}\right)$ and $\mathrm{Ca}\left(1.1 \mathrm{~mol} \mathrm{~kg}^{-1}\right)$ contents, (Fig. 3) although these represent only small fractions of the bulk sample contents $(<0.04 \%$ for $\mathrm{As}$ and $\mathrm{Fe}$, and $0.8 \%$ for $\mathrm{Ca})$. The $\mathrm{Fe} / \mathrm{As}$ molar ratio of the $\mathrm{WP}_{\mathrm{DCF}}(\mathrm{Fe} / \mathrm{As}=0.94)$ was half that of the bulk WP(1.96). The $\mathrm{WP}_{\mathrm{DCF}}$ and $\mathrm{RB} 2_{\mathrm{DCF}}$ the smallest colloid masses per mass of bulk sample (Table 1).

The bulk RB2 sample, collected close to the waste pile (Fig. 1), had more acidic pH (3.86) and higher As and Fe concentrations than the RB, SS and SP bulk samples. However, when normalized to the mass of the bulk sample, the As and Fe concentrations of the RB2 $2_{\mathrm{DCF}}$ were lower than in the other downstream samples $(0.2 \%$ and $0.07 \%$ of the 
total As and Fe contents of the RB2 bulk sample). The bulk RB2 and the RB2 ${ }_{\mathrm{DCF}}$ had the lowest $\mathrm{Ca}$ concentrations. Zinc and $\mathrm{Pb}$ concentrations of the RB2, RB, SS and SP bulk samples were similar. The RB2 bulk sample was richer in $\mathrm{Cu}$ than in $\mathrm{Zn}$ or $\mathrm{Pb}$. Copper concentration increased in the downstream RB and SS bulk samples, but decreased in the SP bulk sample. A similar trend was observed in the DCF of these samples (although no $\mathrm{Cu}$ was detected in $\mathrm{RB} 2$ DCF) (Fig. 8). The bulk RB sample had a higher $\mathrm{pH}$ (4.3) and higher organic carbon (OC) content than the bulk RB2 sample (Table EA-1). The total As concentration of the RB2 bulk sample was one order of magnitude greater than that of the RB bulk sample. In contrast, the As concentration per mass of bulk sample in $\mathrm{RB}_{\mathrm{DCF}}$ was greater than in $\mathrm{RB} 2{ }_{\mathrm{DCF}}$ (Fig. 8). The $\mathrm{RB}_{\mathrm{DCF}}$ As concentration accounted for more than $35 \%$ of the total As in the bulk sample. The XRD pattern of the RB2 and RB bulk samples showed hematite, muscovite, quartz and feldspar to be the primary minerals (Fig. EA-1). The total element composition of the SS bulk sample was similar to that measured for the RB bulk sample (Table EA-1), except that no OC was measured in the SS sample. The SS bulk sample had slightly higher $\mathrm{pH}$ (4.5) than the RB bulk sample and similar XRD pattern, although no hematite was detected (Fig. EA-1). The $\mathrm{SS}_{\mathrm{DCF}}$ had greater colloid mass than the $\mathrm{RB}_{\mathrm{DCF}}$, and contained less As and Fe, but more $\mathrm{Ca}$ (Fig. 8). The greatest colloid mass per mass of bulk sample was obtained for the SP bulk sample (17644 mg kg${ }^{1}$ ); the bulk SP (Table EA 1) and $\mathrm{SP}_{\mathrm{DCF}}$ (Table 1) had the highest $\mathrm{C}$ contents and $\mathrm{pH}(\mathrm{pH}=$ 6.2) of all. The total As concentration of the SP bulk sample $\left(2.3 \mathrm{mmol} \mathrm{kg}^{-1}\right)$ was almost double that of the RB and SS bulk samples $\left(\sim 1.3 \mathrm{mmol} \mathrm{kg}^{-1}\right)$, while the Fe and Ca contents were similar in all three. In contrast, the As and Fe concentrations were lower in the $\mathrm{SP}_{\mathrm{DCF}}$ than in the $\mathrm{RB}_{\mathrm{DCF}}$, and higher than in the $\mathrm{SS}_{\mathrm{DCF}}$, while the $\mathrm{Ca}$ concentration was lower in the $\mathrm{SP}_{\mathrm{DCF}}$ than in the $\mathrm{RB}_{\mathrm{DCF}}$ and $\mathrm{SP}_{\mathrm{DCF}}$ (Fig. 8). The As concentration of the $\mathrm{SS}_{\mathrm{DCF}}$ and 
$\mathrm{SP}_{\mathrm{DCF}}$ were 0.12 and $0.24 \mathrm{mmol} \mathrm{kg} \mathrm{soil}^{-1}$ respectively, representing $\sim 10 \%$ of the total As concentration of the corresponding bulk samples.

Low As and Fe concentrations were found in all dissolved fractions DFs $(<10 \mathrm{~nm})$ (Table EA-5, Fig. 8). The $\mathrm{SS}_{\mathrm{DF}}$ had the highest As concentration, $(0.5 \%$ of the total As content of the bulk SS sample). Iron was detected only in the $\mathrm{WP}_{\mathrm{DF}}$ and $\mathrm{RB} 2_{\mathrm{DF}}$. The $\mathrm{Al}$ concentration was low in all the dissolved fractions. The DF concentrations of $\mathrm{Ca}, \mathrm{Cu}, \mathrm{Zn}$, and $\mathrm{Pb}$ were higher than in the corresponding DCFs (especially with respect to WP and RB2) (Fig. 8). Finally, lower $\mathrm{Ca}, \mathrm{Cu}$ and $\mathrm{Zn}$ concentrations were observed in the $\mathrm{RB}_{\mathrm{DF}}$, $\mathrm{SS}_{\mathrm{DF}}$ and $\mathrm{SP}_{\mathrm{DF}}$ than in the $\mathrm{WP}_{\mathrm{DF}}$ and $\mathrm{RB} 2_{\mathrm{DF}}$

\section{Discussion}

\subsection{DCF composition and As and Fe speciation}

Nanoparticle scorodite was the main As mineral phase in the $\mathrm{WP}_{\mathrm{DCF}}$, and it has a local atomic structure similar to that of crystalline scorodite at particle sizes of $\sim 80 \mathrm{~nm}$ in diameter). There was no evidence for nanoparticulate scorodite in any other DCF, suggesting dissolution down-gradient of the WP despite its reported low solubility and high stability at $\mathrm{pH} 3-4$ [26].

In the downstream samples, As was mainly associated with Fe(III) oxide phases. The EXAFS spectra showed similar As-Fe interatomic distances in the $\mathrm{RB}_{\mathrm{DCF}}$ and $\mathrm{SP}_{\mathrm{DCF}}$ (3.32 A and 3.31 Å respectively), comparable to that obtained in EXAFS analysis of As(V) adsorbed onto colloidal 2-line ferrihydrite (3.28 $\AA$ ), but shorter than values obtained in the EXAFS fit of As(V) adsorbed onto bulk 2-line ferrihydrite (fit two Fe shells at $3.38 \AA$ and $3.52 \AA$ ) [27]. Differences in the local $\mathrm{As}(\mathrm{V})$ bonding environment between these two reference spectra are probably related to differences in their As/Fe molar ratios and the smaller particle size of colloidal ferrihydrite. The greater proportion of $\mathrm{Al}$ to $\mathrm{Fe}$ in the 
$\mathrm{SS}_{\mathrm{DCF}}$ compared to $\mathrm{RB}_{\mathrm{DCF}}$ and $\mathrm{SP}_{\mathrm{DCF}}$ might explain the lack of strong second-neighbor backscattering in the $\mathrm{SS}_{\mathrm{DCF}}$ spectrum compared to the $\mathrm{RB}_{\mathrm{DCF}}$ or $\mathrm{SP}_{\mathrm{DCF}}$ spectra.

The Fe XANES results for the $\mathrm{SP}_{\mathrm{DCF}}$ suggest a spectral contribution from an Fe-bearing illite-type phase ( $60 \%)$ rather than a smectite phase in addition to iron oxide-type phases. The high Al concentration of the DCFs of the downstream samples, and the TEM-EDS observations, indicate the presence of aluminosilicates generally associated with Fe-rich particles. The adsorption capacity of $\mathrm{Fe}(\mathrm{III})$ oxides and clay minerals for $\mathrm{Ca}, \mathrm{Cu}, \mathrm{Zn}$ and $\mathrm{Pb}[28,29]$ would explain their presence in the downstream sample DCFs (Fig. 4), although this interaction depends on the $\mathrm{pH}$ of the bulk samples (see next section). The $\mathrm{SP}_{\mathrm{DCF}}$ had the greatest colloid mass of all. This might be related to its high $\mathrm{OC}$ content, which can increase the stability of iron-rich nanoparticles [30]. TEM and $\mu$ XRF analysis of $\mathrm{SP}_{\mathrm{DCF}}$ showed the formation of aggregates with strong Fe/As correlations, supporting the idea that As adsorbs onto the Fe (III) phases, as indicated by As XAS.

\subsection{DCF composition and bulk sample properties}

The presence of organic matter, circum-neutral $\mathrm{pH}$, and low ionic strength, increase the stability of soil colloids $[9,11]$. Thus, the high colloid mass associated with the $\mathrm{SP}_{\mathrm{DCF}}$ (Table 1) is likely the result of the high $\mathrm{pH}$, high OC content and low ionic strength of the SP bulk sample (Table EA-1). Both the SP and RB bulk samples have similar C contents; however, the higher $\mathrm{pH}$ of the former may promote the release of organic matter [31], explaining the higher $\mathrm{OC}$ of the $\mathrm{SP}_{\mathrm{DCF}}$ than the $\mathrm{RB}_{\mathrm{DCF}}$. In contrast, the $\mathrm{WP}_{\mathrm{DCF}}$ and $\mathrm{RB} 2_{\mathrm{DCF}}$ showed the smallest colloid masses, probably related to the acidic $\mathrm{pH}$ and undetectable OC content of their bulk samples. This might also be related to the high $\mathrm{Ca}^{2+}$ concentration of the WP bulk sample hindering colloid release $[32,33]$. The higher $\mathrm{Ca}^{2+}$ content of the $\mathrm{SS}_{\mathrm{DCF}}$ than of the $\mathrm{RB}_{\mathrm{DCF}}$ or $\mathrm{SP}_{\mathrm{DCF}}$ might also be associated with the formation of the large aggregates observed (Fig. 5). 
Normalized to the bulk sample mass, the higher As concentration of the $\mathrm{RB}_{\mathrm{DCF}}(>35 \%$ of the total $\mathrm{As}$ in $\mathrm{RB}$ ) compared to the $\mathrm{SS}_{\mathrm{DCF}}$ and $\mathrm{SP}_{\mathrm{DCF}}$ may be related to its smaller colloid size. The specific surface area is related to the particle size and determines the adsorption capacity of colloids [2]. Accordingly, higher As concentrations are expected for samples with smaller particles sizes, such as the RB bulk sample. This trend, however, was not seen for $\mathrm{Ca}, \mathrm{Cu}, \mathrm{Zn}$ or $\mathrm{Pb}$, since their retention on $\mathrm{Fe}$ (oxy)hydroxide and clay nanoparticles at the $\mathrm{pH}$ of the $\mathrm{RB}(\mathrm{pH}=4.3)$ is not favored.

The Fe (oxy)hydroxide nanoparticles present in the DCFs may either have formed in the DCF or have been mobilized from the bulk samples. In the SP bulk sample, the precipitation of Fe oxide particles might be associated with its higher $\mathrm{pH}$ [31]; Fe solubility decreases with increasing $\mathrm{pH}$ [34]. Given the acidic $\mathrm{pH}$ of the remaining samples, $\mathrm{Fe}$ (oxy)hydroxide and clay mineral particles would originate mostly through their mobilization from the bulk samples. Calcium, $\mathrm{Cu}, \mathrm{Zn}$ and $\mathrm{Pb}$ partitioning between the $\mathrm{DCF}$ and DF of the samples might also be affected by $\mathrm{pH}$. In general, samples with lower soil pH (WP and RB2) had DCFs with lower cation concentration, but DF with higher dissolved cation concentration. The opposite behavior was observed in samples which had higher $\mathrm{pH}$, with the exception of $\mathrm{Cu}$ in $\mathrm{SP}$, for which higher $\mathrm{Cu}$ concentration was observed in the DF than in the DCF.

\subsection{Implications for As and metal mobility}

Arsenic was present in the DCF of all samples downstream of the WP mostly associated with colloid-size Fe-(oxy)hydroxides. In the corresponding DFs ( $<10 \mathrm{~nm})$, low As concentrations were observed. The relative amounts of As bound to colloids varied from $1 \%$ to $35 \%$ of the total As concentration in the bulk samples, depending on their $\mathrm{pH}, \mathrm{OC}$ content, ionic strength, and the size distribution of the natural nanoparticles (which determine their surface reactivity [35]). In spite of the differences in these variables, and of 
differences in DCF particle sizes, As adsorption onto Fe-(oxy)hydroxides persisted in the DCF of all the downstream samples, indicating the high affinity of As for nanoparticulate Fe-(oxy)hydroxides [36] and their potential mobility. In addition to the concentration of Fe-(oxy)hydroxide nanoparticles and their potential function as As carriers, the transport of trace metals on colloidal particles depends on local water chemistry $[1,35]$. Since the extraction of the DCF from the samples was performed ex situ using a 1:10 dried bulk sample/solution ratio, results can only be extrapolated to field conditions resulting after rain events following extended dry periods. However, they might represent the potentially removable colloid-bound and dissolved fractions of contaminant elements in natural systems. Further work should include examining the release of colloids in situ in seasonally variable environments.

\section{Conclusions}

This work showed that up to one third of the total As present in bulk samples collected from a mine site and adjacent soils and sediments, was associated with the colloid fraction and very low concentrations were measured in the dissolved fraction $(<10 \mathrm{~nm})$. The acidity, OC content and $\mathrm{Ca}$ concentration of the samples were closely related to the stability or aggregation of colloids, and thus the particle size distribution. Nanoparticle scorodite was only found in the wastepile samples, which suggest the dissolution of this mineral in downstream samples. The persistent association of As and ferrihydrite in the DCF of samples collected downstream of the WP reflects the high affinity of As for nanosize Fe-(oxy)hydroxides particles irrespective of the $\mathrm{pH}$ or $\mathrm{OC}$ content, and suggests a potential role of these nanoparticles as As carriers in natural systems. The combination of AsFIFFF-ICP-MS and X-ray absorption spectroscopy provides fundamental information 
on the partitioning of contaminants in colloid-size particles, as well as their speciation, that contributes to understanding metal(oid) pollution processes in natural systems.

\section{Acknowledgements}

This work was funded by the Spanish Goverment (research project CGL2010-17434). P.A.O. was supported by the US NIEHS Superfund Program (R01 ES016201) and the US National Science Foundation (CHE-1213407). M.A.G.G was supported by the PhD FPI fellowship program (BES-2011-046461). S.S. was supported by the CSIC JAEDoc program (07-00272). XAS measurements made on beamline BM25A (European Synchrotron Radiation Facility) were funded by Projects EC822, CRG25-01-282 and CRG25-01-849. Data collection at the Stanford Synchrotron Radiation Lightsource, SLAC National Accelerator Laboratory, is supported by the U.S. Department of Energy (Contract No. DE-AC02-76SF00515). TEM analyses were performed at Centro Nacional de Microscopía Electrónica (Universidad Complutense de Madrid). ICP-MS analysis were performed at Servicio General de Apoyo a la Investigación-SAI (Universidad de Zaragoza).

\section{References}

[1] R. Kretzschmar, M. Borkovec, D. Grolimund, M. Elimelech, Mobile subsurface colloids and their role in contaminant transport, Adv Agron. 66, (1999) 121-193.

[2] R. Kretzschmar, T. Schafer, Metal retention and transport on colloidal particles in the environment, Elements, 1 (2005) 205-210.

[3] A.D. Karathanasis, D.M.C. Johnson, Subsurface transport of Cd, Cr, and Mo mediated by biosolid colloids, Sci. Tot. Environ. 354 (2006) 157-169. 
[4] M. Hassellöv, K.O. Buesseler, S.M. Pike, M. Dai, Application of cross-flow ultrafiltration for the determination of colloidal abundances in suboxic ferrousrich ground waters, Sci. Tot. Environ. 372 (2007) 636-644.

[5] M. Bauer, C. Blodau, Arsenic distribution in the dissolved, colloidal and particulate size fraction of experimental solutions rich in dissolved organic matter and ferric iron, Geochim. Cosmochim. Acta 73 (2009) 529-542.

[6] P. Sharma, J. Ofner, A. Kappler, Formation of Binary and Ternary Colloids and Dissolved Complexes of Organic Matter, Fe and As, E Environ. Sci. Technol. 44 (2010) $4479-4485$.

[7] K. Tindale, P. Patel, D. Wallschläger, Colloidal arsenic composition from abandoned gold mine tailing leachates in Nova Scotia, Canada, App. Geochem. 26(2011) S260-S262.. [8] J.-M. Séquaris, E. Klumpp, H. Vereecken, Colloidal properties and potential release of water-dispersible colloids in an agricultural soil depth profile, Geoderma, 193-194 (2013) 94-101.

[9] C. Jiang, J.M. Séquaris, H. Vereecken, E. Klumpp, Diffusion-controlled mobilization of water-dispersible colloids from three German silt loam topsoils: effect of temperature, Eur. J. Soil Sci. 64 (2013) 777-786.

[10] R. Kretzschmar, H. Sticher, Transport of Humic-Coated Iron Oxide Colloids in a Sandy Soil:Influence of Ca2+ and Trace Metals, E Environ. Sci. Technol. 31 (1997) 34973504

[11] C. Kjaergaard, Colloid mobilization and transport in structured soils, Ph.D. Dissertation, Department of Environmental Engineering, Aalborg University, 2004.

[12] S. Dubascoux, I. Le Hécho, M. Potin Gautier, G. Lespes, On-line and off-line quantification of trace elements associated to colloids by As-Fl-FFF and ICP-MS, Talanta, 77 (2008) 60-65. 
[13] E. Bolea, F. Laborda, J.R. Castillo, Metal associations to microparticles, nanocolloids and macromolecules in compost leachates: Size characterization by asymmetrical flow field-flow fractionation coupled to ICP-MS, Anal. Chim. Acta, 661 (2010) 206-214.

[14] M. Plaschke, T. Schafer, T. Bundschuh, T.N. Manh, R. Knopp, Size characterization of bentonite colloids by different methods, Anal. Chem. 73 (2001) 4338-4347.

[15] F. Von der Kammer, M. Baborowski, S. Tadjiki, W. Von Tumpling, Colloidal particles in sediment pore waters: Particle size distributions and associated element size distribution in anoxic and re-oxidized samples, obtained by FFF-ICP-MS coupling, Acta Hydrochim. Hydrobiol. 31 (2004) 400-410.

[16] A.J. Slowey, S.B. Johnson, M. Newville, G.E. Brown Jr, Speciation and colloid transport of arsenic from mine tailings, AppGeochem. 22 (2007) 1884-1898.

[17] H. Zänker, H. Moll, W. Richter, V. Brendler, C. Hennig, T. Reich, A. Kluge, G. Hüttig, The colloid chemistry of acid rock drainage solution from an abandoned $\mathrm{Zn}-\mathrm{Pb}-\mathrm{Ag}$ mine, App Geochem. 17 (2002) 633-648.

[18] K.L. Haus, R.L. Hooper, L.A. Strumness, J.B. Mahoney, Analysis of arsenic speciation in mine contaminated lacustrine sediment using selective sequential extraction, HR-ICPMS and TEM, App. Geochem., 23 (2008) 692-704.

[19] L. Recio-Vazquez, J. Garcia-Guinea, P. Carral, A. Alvarez, F. Garrido, Arsenic Mining Waste in the Catchment Area of the Madrid Detrital Aquifer (Spain), Water Air Soil Poll. 214 (2011) 307-320.

[20] F. Laborda, S. Ruiz-Begueria, E. Bolea, J.R. Castillo, Study of the size-based environmental availability of metals associated to natural organic matter by stable isotope exchange and quadrupole inductively coupled plasma mass spectrometry coupled to asymmetrical flow field flow fractionation, J. Chromatogr. A, 1218 (2011) 4199-4205.

[21] B. Ravel, ATHENA User'sGuide 1.5, 2009. 
[22] G.N. George, I.J. Pickering, EXAFSPAK: A suite of computer programs for analysis of X-ray absorption spectra, Stanford Syncrotron Radiation Laboratory, 2000.

[23] K.S. Savage, D.K. Bird, P.A. O'Day, Arsenic speciation in synthetic jarosite, Chemi. Geol.215 (2005) 473-498.

[24] R.A. Root, D. Vlassopoulos, N.A. Rivera, M.T. Rafferty, C. Andrews, P.A. O'Day, Speciation and natural attenuation of arsenic and iron in a tidally influenced shallow aquifer, Geochim. Cosmochim. Acta, 73 (2009) 5528-5553.

[25] P.A. O'Day, N. Rivera, Jr., R. Root, S.A. Carroll, X-ray absorption spectroscopic study of Fe reference compounds for the analysis of natural sediments, Am. Mineral. 89 (2004) 572-585.

[26] D. Paktunc, K. Bruggeman, Solubility of nanocrystalline scorodite and amorphous ferric arsenate: Implications for stabilization of arsenic in mine wastes, AppGeochem. 25 (2010) 674-683.

[27] M. Helmhart, P. O’Day, J. Garcia-Guinea, S. Serrano, F. Garrido, Arsenic, Copper, and Zinc Leaching through Preferential Flow in Mining-Impacted Soils, Soil Sci. Soc. Am. J. 76 (2012) 449-462.

[28] D.A. Dzombak, M.M. Morel F, Surface Complexation Modelling: Hydrous Ferric Oxide, Wiley-Interscience,, New York, 1990.

[29] S. Serrano, P.A. O'Day, D. Vlassopoulos, M.T. Garcia-Gonzalez, F. Garrido, A surface complexation and ion exchange model of $\mathrm{Pb}$ and $\mathrm{Cd}$ competitive sorption on natural soils, Geochim. Cosmochim. Acta 73 (2009) 543-558.

[30] C. Neal, S. Lofts, C.D. Evans, B. Reynolds, E. Tipping, M. Neal, Increasing Iron Concentrations in UK Upland Waters, Aquat.Geochem. 14 (2008) 263-288.

[31] E. Neubauer, W.D.C. Schenkeveld, K.L. Plathe, C. Rentenberger, F. von der Kammer, S.M. Kraemer, T. Hofmann, The influence of $\mathrm{pH}$ on iron speciation in podzol extracts: 
Iron complexes with natural organic matter, and iron mineral nanoparticles, Sci. Tot. Environ. 461-462 (2013) 108-116.

[32] J.F. McCarthy, J.M. Zachara, Subsurface transport of contaminants, Environmental Science \& Technology, 23 (1989) 496-502.

[33] T. Areepitak, J. Ren, Model Simulations of Particle Aggregation Effect on Colloid Exchange between Streams and Streambeds, Environmental Science \& Technology, (2011).

[34] M. Stumm, Chemistry of the Solid-Water Interface, John Wileny \& Sons, New York, 1996.

[35] M. Hassellov, F. von der Kammer, Iron Oxides as Geochemical Nanovectors for Metal Transport in Soil-River Systems, Elements, 4 (2008) 401-406.

[36] S. Dixit, J.G. Hering, Comparison of Arsenic(V) and Arsenic(III) Sorption onto Iron Oxide Minerals: Implications for Arsenic Mobility, Environ. Sci.Technol. 37 (2003) 41824189.

[37] U. Schwertmann, R.M. Cornell, Iron oxides in the laboratory: Preparation and characterization, WILEY-VCH Verlag GmbH, Weinheim, Germany, 2007.

[38] Y. Xu, G.-P. Zhou, X.-F. Zheng, Redetermination of iron(III) arsenate dihydrate, Acta Crystallogr. E 63 (2007) i67-i69. 


\section{FIGURE CAPTIONS}

FIGURE 1. Location of the area of study. A: Abandoned processing plant with waste pile in the foreground. B: Plan of sampling locations (WP, RB2, RB, SS, SP).

FIGURE 2.Procedure for fractionation and characterization of DCF and DF extracted from bulk samples.

FIGURE 3.Elemental composition ( $\mathrm{mol} \mathrm{kg}^{-1}$ colloid) of the DCF (10-1000 nm).

FIGURE 4.AsFFF-ICP-MS fractograms for the $<1000 \mathrm{~nm}$ fractions of the RB, SS and SP samples showing ICP-MS counts per second (cps) as a function of particle size.

FIGURE 5. Transmission electron microscopy and energy dispersive X-ray spectroscopy analysis of colloid fractions. a) Scorodite nanoparticle in WP, b) heteroaggregates (clay minerals and iron particles) in RB2, c) and d) iron nanoparticles and aggregates in $\mathrm{RB}, \mathrm{e}$ ) aggregates of iron nanoparticles in SS, and f) arsenic identified in aggregates of iron nanoparticles and clay minerals in SP, g) and h) synchrotron $\mu \mathrm{XRF}$ element maps of colloid particles in SP.

FIGURE 6.Arsenic K-edge XANES, EXAFS and Fourier transformations (FT) of DCF from the WP, RB, SS and SP samples (only XANES was performed for RB2). The XANES spectra show the deconvolution of the LCF with the reference scorodite [23] and arsenate adsorbed onto hydrous ferric oxide [As(V)_Fh] [24] (fit results in Table 2). EXAFS were fit using a nonlinear least squares shell-by-shell approach (fitting results in Table EA-6).

FIGURE 7.Iron K-edge XANES, EXAFS and Fourier transformations (FT) of the DCF from the WP, RB2, RB, SS and SP samples. XANES show the deconvolution of the LCF with the reference smectite (SAz-1) (Clay Minerals Society Source Clays Repository), scorodite [23], and the reference As adsorbed onto ferrihydrite $\left(\mathrm{Fh} \_\mathrm{As}(\mathrm{V}) \_c o l l\right)(\mathrm{As} / \mathrm{Fe}=0.09)($ synthetic two-line ferrihydrite prepared as in [37]). The 
same reference compounds were used for linear least-squares combination fits for $\mathrm{Fe}$

EXAFS. Solid lines are data; dashed lines are fits (fit results in Table 3).

FIGURE 8.Element concentrations ( $\mathrm{mol} \mathrm{kg}^{-1}$ sample) in the DCFs $(10-1000 \mathrm{~nm})$ and

DFs $(<10 \mathrm{~nm})$.

Table 1. Dispersible colloid fraction $(10-1000 \mathrm{~nm})$ properties (mean \pm std dev, $\mathrm{n}=3$ )

\begin{tabular}{l|lllll}
\hline Sample & WP & RB2 & RB & SS & SP \\
\hline $\begin{array}{l}\text { Colloidal mass (mg/ } \\
\text { kg sample) }\end{array}$ & $2636 \pm 494$ & $840 \pm 126$ & $7501 \pm 849$ & $4884 \pm 710$ & $17645 \pm 264$ \\
$\mathrm{As}(\mathrm{mol} / \mathrm{kg}$ colloid) & $0.25 \pm 0.004$ & $0.08 \pm 0.007$ & $0.07 \pm 0.015$ & $0.02 \pm 0.002$ & $0.01 \pm 0.04$ \\
$\mathrm{Fe}(\mathrm{mol} / \mathrm{kg}$ colloid) & $0.27 \pm 0.014$ & $0.57 \pm 0.022$ & $3.97 \pm 0.084$ & $0.96 \pm 0.128$ & $1.08 \pm 2.20$ \\
$\mathrm{Ca}(\mathrm{mol} / \mathrm{kg}$ colloid) & $3.55 \pm 1.39$ & $0.30 \pm 0.066$ & $0.04 \pm 0.001$ & $0.15 \pm 0.001$ & $0.09 \pm 0.28$ \\
$\mathrm{Al}(\mathrm{mol} / \mathrm{kg}$ colloid) & b.d. & $1.54 \pm 0.076$ & $4.27 \pm 0.078$ & $6.57 \pm 0.07$ & $4.25 \pm 3.99$ \\
$\mathrm{Cu}(\mathrm{mol} / \mathrm{kg}$ colloid) & b.d & b.d & $0.02 \pm 0.000$ & $0.05 \pm 0.002$ & $2.7 \times 10^{-3} \pm 0.01$ \\
$\mathrm{Zn}(\mathrm{mol} / \mathrm{kg}$ colloid) & b.d. & $0.01 \pm 5 \times 10^{-4}$ & $6.9 \times 10^{-3} \pm 1 \times 10^{-4}$ & $5.5 \times 10^{-3} \pm 5 \times 10^{-5}$ & $2.1 \times 10^{-3} \pm 6 \times 10^{-3}$ \\
$\mathrm{~Pb}(\mathrm{~mol} / \mathrm{kg}$ colloid) & $5.3 \times 10^{-3} \pm 1 \times 10^{-4}$ & b.d. & b.d. & b.d. & b.d. \\
$\mathrm{C}(\mathrm{mol} / \mathrm{kg}$ colloid) & $0.67 \pm 0.002$ & -- & $0.7 \pm 0.002$ & $0.6 \pm 0.0092$ & $3.49 \pm 0.02$ \\
\hline
\end{tabular}

b.d.: below detection limit; --: not detected

Table 2: Arsenic X-ray absorption near edge structure (XANES) and extended X-ray absorption fine structure (EXAFS) fits results.

\begin{tabular}{|c|c|c|c|c|c|c|c|c|c|c|}
\hline & $\begin{array}{l}\text { Molar } \\
\mathrm{As} / \mathrm{Fe}\end{array}$ & $\begin{array}{l}\text { XANES } \\
(\%)^{\mathrm{a}}\end{array}$ & As EX & & & & & & KRD & \\
\hline Sample & & & $A-B^{d}$ & $N$ & $R(\AA)$ & $\sigma^{2}\left(\AA^{2}\right)$ & $\Delta E_{\mathrm{O}}(\AA)$ & $\chi^{2}$ & $\mathrm{~N}$ & $R(\AA)$ \\
\hline WP & 0.88 & a. 61.3 & As-O & $4.0^{\mathrm{f}}$ & 1.69 & $0.0027^{f}$ & -0.66 & 3.26 & & \\
\hline & & b. $38.7^{\mathrm{e}}$ & $\mathrm{MS}^{\mathrm{g}}$ & 1.0 & $3.07 /$ & $0.0050 /$ & & & & \\
\hline & & & $\mathrm{As}-\mathrm{Fe}$ & $3.7^{\mathrm{f}}$ & 3.37 & 0.0062 & & & & \\
\hline & & & As-As & $0.8^{\mathrm{f}}$ & 4.22 & 0.0079 & & & & \\
\hline & & & As-As & $1.9^{\mathrm{f}}$ & 4.93 & 0.0089 & & & & \\
\hline RB2 & 0.16 & $100.3^{\mathrm{h}}$ & & & & & & & & \\
\hline RB & 0.016 & $94.5^{h}$ & As-O & 4.0 & $1.68^{\mathrm{c}}$ & $0.0023^{\mathrm{f}}$ & -1.3 & 1.37 & & \\
\hline & & & $\mathrm{MS}^{\mathrm{g}}$ & 1.0 & $3.06 /$ & $0.0035 /$ & & & & \\
\hline & & & As-Fe & $1.9^{\mathrm{f}}$ & $3.32^{\mathrm{f}}$ & 0.006 & & & & \\
\hline SS & 0.027 & $101.0^{\mathrm{h}}$ & As-O & 4.0 & $1.69^{f}$ & $0.0024^{f}$ & -0.56 & 3.7 & & \\
\hline & & & $M S^{g}$ & 1.0 & $3.06 /$ & $0.0032 /$ & & & & \\
\hline & & & $\mathrm{As}-\mathrm{Fe}$ & $0.6^{\mathrm{f}}$ & $3.40^{\mathrm{f}}$ & 0.006 & & & & \\
\hline SP & 0.013 & $108.3^{\mathrm{h}}$ & As-O & $4.0^{f}$ & $1.69^{f}$ & 0.0028 & -1.09 & 1.36 & & \\
\hline & & & $\mathrm{MS}^{\mathrm{g}}$ & 1.0 & $3.06 /$ & $0.0035 /$ & & & & \\
\hline & & & $\mathrm{As}-\mathrm{Fe}$ & $1.2^{\mathrm{f}}$ & $3.31^{\mathrm{f}}$ & 0.006 & & & & \\
\hline Scorodite $^{i}$ & 1 & & As-O & 4.0 & $1.69^{f}$ & $0.0027^{\mathrm{f}}$ & 1.3 & 1.85 & 4 & 1.67- \\
\hline & & & $\mathrm{MS}^{\mathrm{g}}$ & 1.0 & $3.07 /$ & $0.0050 /$ & & & 2 & 3.06 \\
\hline & & & $\mathrm{As}-\mathrm{Fe}$ & 4.0 & $3.37^{\mathrm{f}}$ & $0.0062^{f}$ & & & 4 & $3.37-$ \\
\hline & & & & & & & & & & 3.39 \\
\hline & & & As-As & 1.0 & $4.20^{\mathrm{f}}$ & $0.0079^{f}$ & & & 1 & 4.22 \\
\hline & & & As-As & 2.0 & $4.91^{\mathrm{f}}$ & $0.0089^{f}$ & & & 2 & 4.91 \\
\hline
\end{tabular}




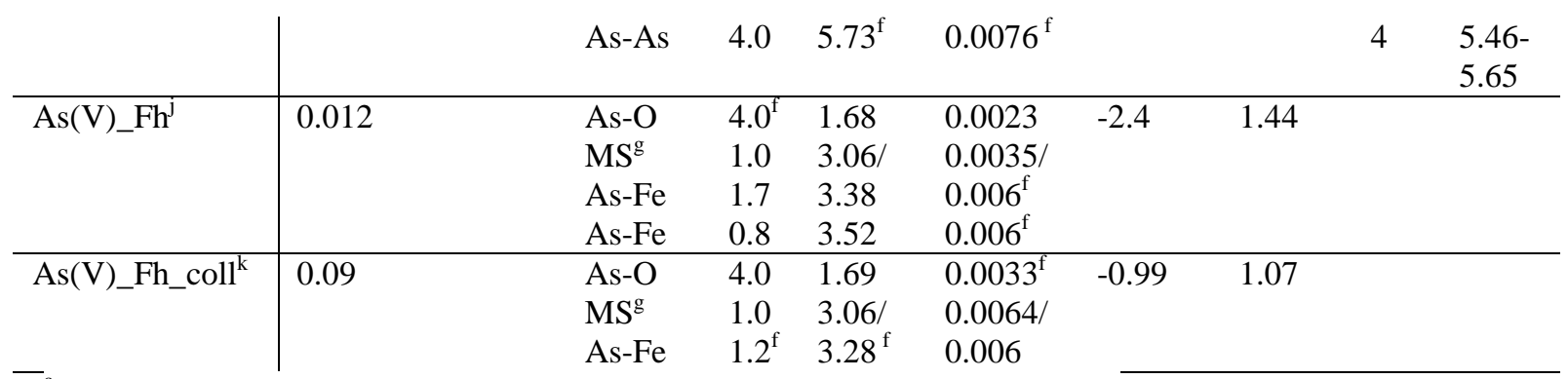

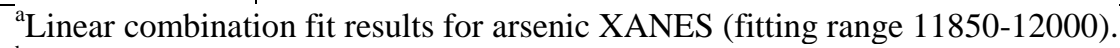

${ }^{\mathrm{b}}$ Results of As EXAFS shell-by-shell fits for reference compounds and colloids.

${ }^{\mathrm{c} C}$ Crystallographic distances from from Xu et al. [38].

${ }^{\mathrm{d}} \mathrm{A}-\mathrm{B}$ is the absorber-backscatterer pair; $\mathrm{N}$ is the number of backscattering atoms at distance $(\mathrm{R}) ; \sigma^{2}$ (Debye Waller term) is the absorber-backscatterer mean-square relative displacement; $\Delta E_{\mathrm{O}}$ is the energy shift in the least-squares fit; $\chi^{2}$ is a reduced least-squares goodness-of-fit parameter (=(F-factor)/(\#points -\#variables)); scale factor $\left(\mathrm{S}^{2}{ }_{0}\right)$ fixed at 1.

${ }^{\text {e}}$ Fraction corresponded to (a.) scorodite (spectrum from Savage et al.[23], and (b.) arsenate sorbed to hydrous ferric oxide (As(V)_Fh); spectrum from Root et al. [24] and refit in Helmhart et al.[27].

${ }^{f}$ Parameter allowed to vary during the fitting; / parameter linked to the parameter inmediately above in the fitting.

${ }^{g}$ Spectrum fit with multiple scattering path that is a composite of 6 triangular paths $(\mathrm{O} \rightarrow \mathrm{O} \rightarrow \mathrm{As})$.

${ }^{\mathrm{h}}$ Fraction corresponded to Arsenate sorbed to hydrous ferric oxide (As(V)_Fh) (\%) spectrum from Root et al. [24] and refit in Helmhart et al. [27].

${ }^{i}$ Natural scorodite $\left(\mathrm{FeAsO}_{4} 2 \mathrm{H}_{2} \mathrm{O}\right)$ spectrum from Savage et al.[23].

${ }^{j}$ Arsenate sorbed to hydrous ferric oxide (As(V)_Fh); spectrum from Root et al. [24] and refit in Helmhart et al. [27].

${ }^{\mathrm{k}}$ Arsenate sorbed to colloidal hydrous ferric oxide (As(V)_Fh_coll) from this study.

Table 3: Linear combination fit results for iron X-ray absorption near edge structure (XANES) and extended X-ray absorption fine structure (EXAFS)

\begin{tabular}{|c|c|c|c|c|c|c|c|c|c|c|c|}
\hline Sample & $\begin{array}{l}\text { Fitting } \\
\text { range }\end{array}$ & $\begin{array}{l}\text { Scorodite } \\
(\%)^{\mathrm{b}}\end{array}$ & $\Delta \mathrm{eV}$ & $\begin{array}{l}\text { As_Fh_coll } \\
(\%)^{\mathrm{c}}\end{array}$ & $\Delta \mathrm{eV}$ & $\begin{array}{l}\text { Smectite } \\
(\%)^{\mathrm{d}}\end{array}$ & $\Delta \mathrm{eV}$ & $\begin{array}{l}\text { Illlite } \\
(\%)^{\mathrm{e}}\end{array}$ & $\Delta \mathrm{eV}$ & $\begin{array}{l}\text { Total } \\
(\%)\end{array}$ & red. $\chi^{2 f}$ \\
\hline $\begin{array}{l}F e \\
X A N E S\end{array}$ & $\begin{array}{l}\text { Energy } \\
(\mathrm{eV})\end{array}$ & & & & & & & & & & \\
\hline WP & $7105-7160$ & $\begin{array}{l}82.6 \\
3.4^{\mathrm{g}}\end{array}$ & 0.03 & $\begin{array}{l}16.4 \\
16.6^{\mathrm{g}}\end{array}$ & 0.2 & & & & & 99 & 0.000058 \\
\hline RB2 & $7105-7160$ & & & 100 & 0.2 & & & & & 100 & 0.000050 \\
\hline RB & $7105-7160$ & & & $\begin{array}{l}62.3^{\mathrm{g}} \\
60.2^{\mathrm{g}}\end{array}$ & 0.39 & $\begin{array}{l}41.2^{g} \\
39.7^{g}\end{array}$ & -0.2 & & & 103 & 0.000147 \\
\hline SS & $7105-7160$ & & & $\begin{array}{l}44.6 \\
43.3^{\mathrm{g}}\end{array}$ & 0.02 & $\begin{array}{l}58.3^{\mathrm{g}} \\
56.6^{\mathrm{g}}\end{array}$ & -0.09 & & & 103 & 0.000139 \\
\hline SP & $7105-7160$ & & & $\begin{array}{l}39.3 \\
39.5^{\mathrm{g}}\end{array}$ & 0.04 & & & $\begin{array}{l}59.7 \\
60^{\mathrm{g}}\end{array}$ & -0.45 & 99 & 0.000093 \\
\hline Sample & $\begin{array}{l}\text { Fitting } \\
\text { range }\end{array}$ & Scorodite & & As_Fh_coll & & Smectite( & & Illlite (\%) & & $\begin{array}{l}\text { Total } \\
(\%)\end{array}$ & red. $\chi^{2 \mathrm{f}}$ \\
\hline $\begin{array}{l}F e \\
E X A F S\end{array}$ & $\mathrm{k}\left(\stackrel{\circ}{ }^{-1}\right)$ & & & & & & & & & & \\
\hline WP & $2-11$ & $\begin{array}{l}81.9 \\
68.8^{\mathrm{g}}\end{array}$ & & $\begin{array}{l}37.9 \\
31.06^{\mathrm{g}}\end{array}$ & & & & & & 119 & 0.45 \\
\hline RB2 & $2-11$ & & & $\begin{array}{l}103.3 \\
100^{\mathrm{g}}\end{array}$ & & & & & & 103 & 0.40 \\
\hline $\mathrm{RB}$ & $2-11$ & & & $\begin{array}{l}32 \\
41.2^{\mathrm{g}}\end{array}$ & & $\begin{array}{l}45.6 \\
58.7^{\mathrm{g}}\end{array}$ & & & & 78 & 0.50 \\
\hline SS & $2-11$ & & & $\begin{array}{l}34.0 \\
42^{\mathrm{g}}\end{array}$ & & $\begin{array}{l}47 \\
58^{\mathrm{g}}\end{array}$ & & & & 81 & 0.30 \\
\hline SP & $2-11$ & & & $\begin{array}{l}25.2 \\
27^{\mathrm{g}}\end{array}$ & & & & $\begin{array}{l}68.1 \\
73^{\mathrm{g}}\end{array}$ & & 93 & 0.93 \\
\hline
\end{tabular}


${ }^{\mathrm{b}}$ Fit with natural scorodite spectrum from Savage et al. [23] /and fit in this study (Table EA-7).

${ }^{c}$ Fit with As(V)_Fh_coll spectrum synthesized and analyzed in this study (Fig. 7, Table 9).

${ }^{\mathrm{d}}$ Fit with reference smectite (SAz-1), Clay Minerals Society reference mineral previously analyzed by

O’Day et al. [25]

${ }^{\mathrm{e}}$ Fit with reference illite (IMt-1), Clay Minerals Society reference mineral previously analyzed by O’Day et al. [25]

${ }^{\mathrm{f}}$ Goodness-of fit reported as reduced $\chi^{2}$ calculated as three times the estimated standard deviation for each component from the linear least-squares fit.

${ }^{\mathrm{g}}$ Recalculated to Total $100 \%$ 